\title{
Metastasis of genitourinary tumors to the head and neck region
}

\author{
Ore Ogunyemi $\cdot$ A. Rojas $\cdot$ K. Hematpour $\cdot$ \\ D. Rogers $\cdot$ C. Head $\cdot$ C. Bennett
}

Received: 14 September 2008 / Accepted: 3 June 2009 / Published online: 18 June 2009

(C) The Author(s) 2009. This article is published with open access at Springerlink.com

\begin{abstract}
The objective of the present study is to characterize genitourinary tumors (GU) metastatic to the head and neck and to determine long-term prognoses. Using a retrospective chart review of 734 patients treated between January 1995 and May 2005 with an ICD-9 code pertaining to a metastatic head and neck cancer, we found 37 patients with primary GU tumors. There were 24 cases of prostate cancer, 10 cases of renal cell carcinoma, and 4 cases of transitional cell carcinoma. Sixteen of 24 patients $(67 \%)$ with prostate cancer had a cranial metastasis while 6 of $9(67 \%)$ patients with renal cell carcinoma had cerebral metastasis. We concluded that prolonged survival is possible in prostate cancer patients treated aggressively with radiation and
\end{abstract}

O. Ogunyemi $\cdot$ A. Rojas $\cdot$ C. Bennett

David Geffen School of Medicine at UCLA,

Los Angeles, CA, USA

K. Hematpour

Department of Internal Medicine, St Luke's-Roosevelt Hospital, Columbia University College of Physicians and Surgeons,

New York, NY, USA

D. Rogers

Department of Pathology,

Greater Los Angeles VA Medical Center, Los Angeles, CA, USA

C. Head

Department of Otolaryngology, Greater Los Angeles VA Medical

Center, Los Angeles, CA, USA

C. Bennett

Department of Urology, Greater Los Angeles VA Medical Center, Los Angeles, CA, USA

\section{Bennett $(\square)$}

Department of Urology, Greater Los Angeles Healthcare System, 11301 Wilshire Blvd. (10H2), Los Angeles, CA 90073, USA

e-mail: carol.bennett@med.va.gov chemotherapy, indicating that early detection and aggressive screening are important in these patients.

Keywords Carcinoma of the prostate .

Renal cell carcinoma - Transitional cell carcinoma .

Genitourinary tumors

\section{Introduction}

Head and neck cancer is the fifth most common cancer worldwide [1]. In the United States, head and neck cancers account for $3.3 \%$ of all malignancies [2]. The cervical lymph nodes are a common site of metastasis for cancers originating in the upper aerodigestive tract. Rarely, cancers originating from sites other than the head and neck can metastasize to the cervical lymph node chain. However, genitourinary tract neoplasms make up a significant proportion of these cancers and should be considered in the differential diagnosis of neoplastic lesions of the head and neck [3]. A study reported and identified 31 (3.7\%) of 845 genitourinary tumors metastasized to the head and neck and 21 tumors $(2.5 \%)$ metastasized to the cervical lymph nodes [3]. Ferlito et al. [4] reported a series of genitourinary tumors and found this group to be the third most frequent tumor site to metastasize to the supraclavicular fossa.

Epithelioid tumors in the head and neck are common and include both primary and metastatic lesions [5]. Metastatic lesions, clinical factors, tumor location, and ancillary immunohistochemical studies must be taken into consideration to help the clinician and the pathologist to determine the site of origin. A group of unusual, but important, primary tumors that can metastasize to the head and neck are genitourinary tumors consisting of carcinoma of the prostate (CAP), renal cell carcinoma (RCC), which is also 
known as clear cell carcinoma, and bladder cancer, of which the most common type by far is transitional cell carcinoma (TCC) [6].

Prostate carcinoma is the second most common cause of cancer death among American men [7]. It has been established that more than $30 \%$ of men over the age of 50 will develop this devastating disease [8]. Established risk factors include age, ethnicity and family history [9]. Although most of the metastatic prostate cancers will arise in the axial skeleton or the pelvic lymph nodes, it has been reported to spread to the axillary and cervical lymph nodes of the head and neck region [3, 4]. A retrospective study identified 26 cases of metastatic prostatic carcinoma involving the supraclavicular lymph nodes, which were the most common site of invasion [4]. One study reported 26 cases in which the most common primaries with metastasis to the sphenoid sinus were prostate adenocarcinoma, with an incidence of $20 \%$ [10]. Ferlito et al. [4] reported 5 of 21 cases $(24 \%)$ were normal for serum acid phosphatase, 7 of 20 cases $(35 \%)$ had no evidence of metastases to bones, 8 of $19(42 \%)$ cases had normal rectal examination and 19 of 26 cases presented with physical findings of urinary obstructive symptoms or enlarged lymph nodes despite no history of prostate cancer. This shows that the diagnosis of prostate cancer cannot rely only on clinical or serological examination. Rather it also depends highly on the combination of cytological or histological features with immunostaining using prostate-specific antigen and prostatic acid phosphatase.

Renal cell carcinoma accounts for $3 \%$ of all malignancies and can metastasize to any location in the body, and its propensity to metastasize to unusual sites has been well documented. Approximately, 30\% of patients with RCC present with metastatic disease, $25 \%$ with locally advanced renal carcinoma, and $45 \%$ with localized disease [11]. It is the third most frequent neoplasm to metastasize to the head and neck region preceded only by breast and lung cancer [12]. In spite of being reported infrequently, head and neck region metastases may be linked to RCC in up to $8-15 \%$ of cases [11]. Specifically, regions in the head and neck include the paranasal sinuses, larynx, jaws, temporal bones, thyroid gland, and parotid glands [13, 14]. RCC metastases to the nose and paranasal sinuses are most commonly affected followed by the tongue [15].

In a minority of patients, the classical presentation of RCC manifests itself in the classical triad of pain, hematuria, and flank mass. Unfortunately, head and neck metastasis from RCC is usually a manifestation of widespread disease and it is often indicative of advanced disease. RCC may remain clinically occult for most of its course. The expected 5- and 10-year survival rates for these patients are 5-30 and 0-5\%, respectively [11]. Approximately, 75\% of patients with RCC metastasize most commonly to the lungs, $20 \%$ to bone, $18 \%$ to liver, $36 \%$ to soft tissue and $8 \%$ to central nervous system [16].

Bladder neoplasm accounts for 2-6\% of all tumors, with bladder cancer becoming the fourth most common cancer occurring in the United States, with an increase in incidence after 65 years [17]. Bladder cancer is the second most prevalent cancer for men and the tenth most prevalent cancer for women [17]. Bladder carcinoma metastases are commonly found in bone $(75 \%)$, followed by lymph nodes (26\%) and lung (20\%) [4]. Supraclavicular lymph node metastases are rare and indicate widespread disease with poor prognosis. Metastases of the head and neck regions are also uncommon and their most frequent sites are the brain, supraclavicular nodes, neck nodes and the skull [3]. Hessan et al. [3] reported and identified 3 of 207 cases (1.4\%) for cervical lymph nodes. Very few cases of TCC metastasize to the oral cavity, including one reported case in the maxilla [18] and seven reports identified in the mandible [19]. Only four cases have been described in the oral soft tissues one in the tongue [20] and one in the submandibular gland [21].

Metastatic tumors to the head and neck are extremely rare. Therefore, the literature is based largely on sporadic case reports. Possible routes of metastasis to the head and neck include arterial, venous and lymphatic circulations. These include paravertebral venous plexus (Batson's) or through the thoracic lymphatic duct. Overall, correct diagnosis is important, as these patients may achieve remission and prolonged survival with chemotherapy, irradiation and/ or hormonal therapy.

\section{Materials and methods}

The Systematized Nomenclature of Medicine (SNOMED) files of the Greater Los Angeles VA Medical System (GLAVAMS) Department of Pathology were searched for cases of metastatic CAP, RCC, and TCC. SNOMED is a newer version of the widely used Decentralized Hospital Computer Program (DHCP) which is a way of classifying medical terms based on topography and morphology. Multiple searches were performed through VISTA system which is a Massachusetts General Hospital Utility MultiProgramming System (MUMPS)-based hospital database. Medical records of 14,756 patients with genitourinary cancers being treated or referred to the GLAVAMS from January 1995 to May 2005 were pulled out. Among those, 734 patients who had an ICD-9 code pertaining to a metastatic head and neck cancer were selected and their medical records were thoroughly studied. All relevant slides were examined, and clinical information was obtained from the referring physician's patient charts (Tables 1, 2 and 3). 
Table 1 Characteristics of prostate cancer (CAP) cases metastatic to the head and neck

\begin{tabular}{|c|c|c|c|c|c|c|c|c|}
\hline Case \# & \multicolumn{2}{|l|}{ Site of mets } & Gleason score & \multicolumn{2}{|c|}{ Presentation of metastasis } & Age at CAP & Survival (years) & Year at mets \\
\hline 1 & \multicolumn{2}{|l|}{ Virchow } & 9 & \multicolumn{2}{|c|}{ Swelling } & 52 & 1 & 1 \\
\hline 2 & \multicolumn{2}{|l|}{ Skull (diffuse) } & $4+X$ & \multicolumn{2}{|c|}{ Pain in cranium } & 54 & 5 & 5 \\
\hline 3 & \multicolumn{2}{|l|}{ Temporal lobe } & 7 & \multicolumn{2}{|c|}{ Incontinence LE weakness } & 69 & 10 & 8 \\
\hline 4 & \multicolumn{2}{|l|}{ Dura matter } & 5 & \multicolumn{2}{|c|}{ Diplopia, blindness } & 74 & $9 \mathrm{a}$ & 1 \\
\hline 5 & \multicolumn{2}{|l|}{ Dura matter } & 7 & \multicolumn{2}{|c|}{ Confusion } & 56 & $10 \mathrm{a}$ & 7 \\
\hline 6 & \multicolumn{2}{|l|}{ Virchow } & 7 & \multicolumn{2}{|c|}{ Neck mass } & 79 & 3 & 1 \\
\hline 7 & \multicolumn{2}{|l|}{ Orbit skull base } & 9 & \multicolumn{2}{|c|}{ Blindness } & 85 & 3 & 2 \\
\hline 8 & \multicolumn{2}{|l|}{ Temporal lobe } & 8 & \multicolumn{2}{|l|}{ HA } & 59 & 5 & 3 \\
\hline 9 & \multicolumn{2}{|l|}{ Virchow } & 8 & \multicolumn{2}{|c|}{ Neck mass } & 80 & 15 & 14 \\
\hline 10 & Virchow & & 6 & Neck m & & 57 & 13 & 9 \\
\hline 11 & Midbrain, cave & ous sinus & NA & Right he & weakness & 75 & 4 & 3 \\
\hline 12 & Brain (diffuse) & & 7 & Disequi & ium & 62 & 9 & 1 \\
\hline 13 & Virchow & & 9 & Neck m & & 57 & 7 & 7 \\
\hline 14 & Orbit frontal lo & & NA & Proptosi & tosis redness & 70 & 7 & 6 \\
\hline 15 & Brain (diffuse) & & 7 & Confusi & seizure & 63 & 2 & 2 \\
\hline 16 & Temporal lobe & & 7 & Left sid & eakness & 52 & 5 & 4 \\
\hline 17 & Parotid & & 9 & VII cran & nerve palsy & 62 & 1 & 1 \\
\hline 18 & Clivus & & NA & XII cran & nerve palsy & 59 & 5 & 5 \\
\hline 19 & Brain (diffuse) & & NA & NA & & 58 & 10 & 10 \\
\hline 20 & Sphenoid & & 7 & Left sid & perreflexia, anisocoria & 71 & 10 & 10 \\
\hline 21 & Orbit dura mat & & NA & Blindne & Ind headache & 63 & 3 & 2 \\
\hline 22 & Virchow & & NA & Neck m & & 75 & 4 & 2 \\
\hline 23 & Virchow & & 8 & Neck m & & 59 & 2 & 1 \\
\hline 24 & Skull (fronto te & poral) & NA & Confusi & & 75 & 4 & 4 \\
\hline Case \# & PSA * serum & Hormone & esponse & & Treatment & & & \\
\hline 1 & 5,500 & $\operatorname{Ref}[1]$ & & & Goserelin, bicalutamid & & & \\
\hline 2 & $>1,000$ & Ref & & & Goserelin, flutamide, T & & & \\
\hline 3 & 4 & Treatmen & late in the cours & f disease & Fronto temporal cranio & my, XRT, gos & lin/flutamide, TL & \\
\hline 4 & 2522 & Sen [2] & & & Luperolide, ketoconaz & , XRT & & \\
\hline 5 & 938 & Sen & & & Goserelin, bicalutimid & lutamide, keto & nazole, TURP & \\
\hline 6 & 279 & Sen & & & Goserelin, bicalutimid & & & \\
\hline 7 & 126 & Sen & & & XRT, goserelin, flutam & & & \\
\hline 8 & 13 & Ref & & & Prostatectomy, goserel & flutamide, ket & onazole, estramu & e, VP 16, XRT \\
\hline 9 & 7869 & Ref & & & Prostatectomy, bicalut & ide, & & \\
\hline 10 & 5.2 & Ref & & & Prostatectomy, goserel & bicalutimide, & cetaxel & \\
\hline 11 & NA & Ref & & & Hormonal TX, XRT, v & lastine, estrar & stine & \\
\hline 12 & 284 & Sen & & & Orchiectomy, hormon & $\mathrm{X}, \mathrm{XRT}$ & & \\
\hline 13 & 14 & Ref & & & XRT, goserelin, bicalu & iide, ketocona & le, flutamide & \\
\hline 14 & 1165 & Ref & & & XRT, leperamide, bica & amide, vinbla & he, estramustine & \\
\hline 15 & 51 & Ref & & & Goserelin, flutamide & & & \\
\hline 16 & $>100$ & Ref & & & Craniotomy, TURP, or & iectomy, chen & herapy & \\
\hline 17 & NA & Ref & & & XRT, estramustine & & & \\
\hline 18 & 66 & Ref & & & XRT, total prostatecto & , bilateral orcl & ctomy & \\
\hline 19 & 214 & NA & & & Luperamide & & & \\
\hline 20 & 46 & Ref & & & XRT, hormonal therap & & & \\
\hline 21 & 13 & Ref & & & XRT, hormonal therap & & & \\
\hline 22 & 4 & Ref & & & XRT, estramustin/taxo & e carboplatin, & & \\
\hline 23 & 9 & Ref & & & Goserelin, bicalutamid & XRT & & \\
\hline 24 & NA & Ref & & & Luperamide, bicalutim & & & \\
\hline
\end{tabular}


Table 2 Metastatic RCC of head and neck region and their characteristics

\begin{tabular}{|c|c|c|c|c|c|c|c|c|}
\hline Case \# & Mets & \multicolumn{2}{|l|}{ Present } & \multicolumn{2}{|c|}{ Age at Dx } & Year at mets & Survival (years) & Tob. \\
\hline 1 & Frontal lobe & \multicolumn{2}{|c|}{ HA, LUE Numbness, weakness } & 24 & & 4 & $17^{\mathrm{a}}$ & - \\
\hline 2 & Cerebellum & \multicolumn{2}{|c|}{$\mathrm{HA}^{\mathrm{b}}, \mathrm{N} / \mathrm{V}$, blurry vision } & 51 & & 0 & 5 & + \\
\hline 3 & Frontal lobe, mandible, scalp & \multicolumn{2}{|c|}{ Cystic lesions in the scalp ${ }^{b}$} & 55 & & 0 & 1 & + \\
\hline 4 & Frontal lobe & \multicolumn{2}{|c|}{ Frontal HA, memory loss } & 53 & & 1 & 3 & - \\
\hline 5 & Frontal, occipital lobes, cerebellum & \multicolumn{2}{|c|}{ Dizziness $^{\mathrm{b}}$, dysarthria, dysphagia } & 58 & & 0 & 1 & + \\
\hline 6 & Parotid & \multicolumn{2}{|l|}{ Parotid mass } & 67 & & 1 & $14^{\mathrm{a}}$ & + \\
\hline 7 & Eye & \multicolumn{2}{|l|}{$\mathrm{c}$} & 55 & & 11 & 14 & + \\
\hline 8 & Tongue & \multicolumn{2}{|l|}{ Tongue cyst } & 27 & & 0 & 1 & - \\
\hline 9 & Brain & \multicolumn{2}{|l|}{ HA } & 62 & & 0 & $<1$ & + \\
\hline Case \# & Pathology & Other mets & \multicolumn{2}{|c|}{$\begin{array}{l}\text { Para-neoplastic } \\
\text { syndromes }\end{array}$} & \multicolumn{4}{|c|}{ Treatments } \\
\hline 1 & $\begin{array}{l}\text { Poorly differentiated carcinoma, } \\
\text { staining for GFAP }\end{array}$ & Lung & \multicolumn{2}{|l|}{ None } & \multicolumn{4}{|c|}{$\begin{array}{l}\text { Right frontal lobe craniotomy, } \\
\text { nephrectomy, immune therapy, } \\
\text { chemotherapy }\end{array}$} \\
\hline 2 & Poorly differentiated (grade III), & Bone marrow, liver & \multicolumn{2}{|l|}{ None } & \multicolumn{4}{|c|}{$\begin{array}{l}\text { Nephrectomy, posterior fossa craniotomy, } \\
\text { hepatic wedge resection, chemotherapy, XRT }\end{array}$} \\
\hline 3 & $\mathrm{c}$ & $\begin{array}{l}\text { Adrenal, lungs, } \\
\text { liver, skin }\end{array}$ & \multicolumn{2}{|c|}{ Hypercalcemia } & \multicolumn{4}{|c|}{ IL-2, IFN a, XRT } \\
\hline 4 & Clear cell type (grade II) & None & \multicolumn{2}{|c|}{ Hypercalcemia } & \multicolumn{4}{|c|}{ Nephrectomy, craniotomy } \\
\hline 5 & Clear cell (not graded) & Lungs & \multicolumn{2}{|c|}{ Hypercalcemia } & \multicolumn{4}{|c|}{ XRT } \\
\hline 6 & $\begin{array}{l}\text { Moderately well differentiated } \\
\quad \text { (grade II) }\end{array}$ & Colon & \multicolumn{2}{|c|}{$\begin{array}{l}\text { Polycythemia, } \\
\text { hypercalcemia }\end{array}$} & \multicolumn{4}{|c|}{ Nephrectomy, colectomy } \\
\hline 7 & $\mathrm{c}$ & Bone & \multicolumn{2}{|l|}{ None } & \multicolumn{4}{|c|}{ Nephrectomy, XRT, eye enucleation } \\
\hline 8 & Grade III & Spine, lung, liver & \multicolumn{2}{|c|}{ Hypercalcemia } & \multicolumn{4}{|c|}{ XRT, nephrectomy } \\
\hline 9 & Diagnosed by FNA & Bone, lungs & \multicolumn{2}{|c|}{ Hypercalcemia } & \multicolumn{4}{|c|}{ XRT } \\
\hline
\end{tabular}

${ }^{a}$ Still alive

${ }^{\mathrm{b}}$ Cancer presented with mets

${ }^{c}$ Initial diagnosis and work up at another institution, further records not available

Table 3 Transitional cell carcinoma (TCC) of the bladder with metastasis to the brain

\begin{tabular}{|c|c|c|c|c|c|c|}
\hline Case \# & Site of mets & & Presentation & Pathology & Age at TCC & Survival (years) \\
\hline 1 & Brain (diffuse) & & Headache & NA & 58 & 2 \\
\hline 2 & Cerebellum & & $\begin{array}{l}\text { Gate disturbance, } \\
\text { jerky movements, headache }\end{array}$ & $\begin{array}{l}\text { High grade-poorly } \\
\text { differentiated }\end{array}$ & 73 & 1 \\
\hline 3 & Sphenoid, cavernc & $\mathrm{s}$ sinus & Ptosis, headache & Papillary TCC, grade II & 62 & 1 \\
\hline 4 & Cerebellum & & Headache & High grade TCC & 55 & 7 \\
\hline Case \# & Tobacco & Other sites & Co-morbidities & Treatment & & \\
\hline 1 & 30PY & Spinal cord & High triglyceride & XRT, spinal fusion, trans & hral resection & \\
\hline 2 & $60 \mathrm{PY}$ & Liver, lung & Prostate cancer & Sub-occipital craniotomy & nsurethral rese & \\
\hline 3 & $50 \mathrm{PY}$ & Liver & DVT & XRT & & \\
\hline 4 & None & None & DVT & Transurethral resection, c & hotherapy, sub- & ipital craniotomy \\
\hline
\end{tabular}

\section{Results}

We describe 37 cases of metastatic CAP, RCC, and TCC to the head and neck, consisting of 24 cases of CAP, 9 cases of RCC, and 4 cases of TCC.
Carcinoma of the prostate

Among 24 patients with CAP 16 patients (67) had a cranial metastasis. The location of the metastases consisted of brain, cerebellum, dura, skull, scalp or a combination of 
these. Seven patients (29\%) had a brain metastasis. Five cases $(21 \%)$ had a bony skull metastasis. Three patients (13\%) had a metastasis to the meninges and in two cases $(11 \%)$ there was a pure dural metastasis. One of the cases with a temporal lobe metastasis also had a tumor on the scalp (not in Table). In three out of eight patients (37\%) with brain metastasis, the tumor was found in the temporal lobe. One patient (13\%) had a pure frontal lobe metastasis. Interestingly, both patients with frontal lobe metastases also had orbit and dural involvement. In both cases of dural involvement, the involvement was confined to the frontal dura matter. The base of the skull was a favorite site of involvement in patients with metastasis to the skull. There were two cases with spread to the clivus and base of the skull and one case of sphenoid bone involvement.

Seven patients (29\%) had a tumor in their supraclavicular lymph nodes (Virchow's lymph node). Three cases (13\%) had involvement of the orbit and presented with eye pain, proptosis, or loss of vision, while in one case the tumor cells had spread to the optic nerve. One case (4\%) had involvement of the parotid gland.

The mean Gleason score was 7.5 (range 5-9). However, after reviewing the patient histories in the CPRS system and studying their files in the medical records, eight cases did not have a complete Gleason's grade. Those patients were diagnosed before January 1995 with the primary diagnosis made in another institution.

The average age of onset for the prostate cancer was 62.8 (range 52-85) years and the average years of survival after the diagnosis of CAP was 6.1 years (range 1-15). Two of the 24 patients $(8 \%)$ are alive. The mean survival after the diagnosis of the head and neck metastases was less than 4.5 years. Bone involvement was almost a universal finding among the cases. Only two cases $(11 \%)$ had only soft tissue involvement in the head and neck.

The average PSA at the time of diagnosis was 54.2, which was followed by a drop of the values after the initial treatment. This was followed by a rise before the presentation of the metastases and the average PSA at that time was 958; however, three patients had missing data. All of the cases except for one case were refractory to hormonal therapy. Craniotomy was performed in two patients with a solitary temporal lobe tumor.

Two patients had no history of CAP at the time of biopsy of the head and neck metastasis, and 12 patients (50\%) had other widespread metastatic disease at the time of presentation of the metastases. Histologically, most of the tumors had epithelioid cells with prominent nucleoli and cribriform, solid, or infiltrating single cell growth patterns. PSA and PSAP immunohistochemical stains were positive in all cases except case 14 which had a positive PSA staining and negative PSAP staining. Two of 12 patients with known follow-up are alive after radiation or hormonal therapy.

\section{Renal cell carcinoma}

Among nine patients with RCC with metastases to the head and neck, six patients $(67 \%)$ had metastases to the brain. There was one metastasis each to the parotid gland, the eye, and the tongue $(11 \%)$. One patient among the group had metastases to both the brain and mandible. No metastases to the supraclavicular lymph node were reported. All but one of the patients with brain metastases had frontal lobe involvement; the remaining metastasis was to the cerebellum. One patient had concomitant involvement of the occipital and frontal lobes and cerebellum. The mean age of diagnosis was 50.2 (range 24-67). In five (56\%) patients RCC presented with the head involvement. Two patients developed metastases after 1 year of RCC diagnosis and one patient developed eye metastasis 11 years after the initial diagnosis of the RCC. Two-thirds of the patients were tobacco users with the mean age at the presentation of their cancer of 58 versus 34.6 years in patients without history of tobacco use. Six patients had hypercalcemia at some point during the course of their disease. Three patients with single brain metastasis went through craniotomy and resection of the tumor. The mean survival was 8.6 years after the craniotomy versus 6.2 years in three patients who were not treated with craniotomy.

\section{Transitional cell carcinoma}

In this study, we had four patients with TCC who developed cranial metastases during the course of their disease. Two patients had metastases to the cerebellum, and in both the tumor was resected. All but one of the patients with TCC had over 30 pack year history of tobacco use. One patient with metastasis to the cerebellum lived for 7 years following craniotomy. One patient had metastases to the bony and vascular structures of the skull without brain parenchyma involvement. None of the patients in this group had involvement of the neck or facial structures.

\section{Discussion}

Surgery and radiation therapy, recently augmented by induction chemotherapy, can be effective in the treatment of head and neck carcinomas. These results demonstrate a fair prognosis with possible prolonged survival with metastatic CAP to the head and neck after appropriate diagnosis and subsequent hormone and radiation therapy. Given this survival advantage with treatment, it is critical to consider the diagnosis of metastatic CAP when evaluating a metastatic malignant epithelioid tumor in the head and neck of an elderly man. In this study, temporal lobe was a favorite site for metastasis among patients with intracranial spread of the 
tumor. This finding along with the fact that $50 \%$ of the cases had a single tumor allows for the possibility of potentially improving the patients' prognosis with craniotomy and resection of the tumor. Correct diagnosis is crucial, as these patients may achieve remission and prolonged survival with irradiation and hormonal therapy.

Our results show a clear tendency of RCC to metastasize to the frontal lobe. The second favorite location for this cancer to metastasize was to the cerebellum. It was shown that patients with solitary RCC metastasis to the brain greatly benefit from aggressive intervention and tumor resection. This finding further emphasizes the importance of early detection and management of these metastases in this patient population with special attention to any newly developed headache, and motor or sensory deficit in this group. Including a thorough neurologic examination in each follow-up visit for patients with RCC might have a positive influence on their life expectancy. The finding of lower age of onset in RCC patients without a history of tobacco use might be explained by a genetic propensity for developing cancer in this group. All the patients in the RCC group who had age of onset of over 50 years also had a history of tobacco use. This finding was striking in that it could pose tobacco use as a major risk factor for RCC patients to develop head and neck metastases. This finding was also true in patients with TCC in whom $75 \%$ with brain metastases had a strong history of tobacco use.

In general, the presence of metastases in the patient population with genitourinary cancers heralds a poor prognosis making the discovery of these cancers in the head and neck an oncologically important finding. The negative impact of head and neck metastases was especially shown to be true in prostate cancer patients whereas under certain circumstances patients with metastatic RCC to the head and neck might be good candidates for further intervention and have better outcomes.

Partial or total nephrectomy is the therapeutic approach usually used in metastatic disease to improve the quality of life or symptomatic relief [22]. Treatment of RCC metastasis in the head and neck is directed mainly towards palliation. Excision is usually performed to control pain and to manage any potential complications from a space occupying mass in the head and neck region, including the brain. Radiotherapy can improve symptomatic relief or quality of life for perhaps a few months. Little data exist regarding the use of systemic therapy in the setting of RCC metastasis to the head and neck. Still, most of the patients die within 1 year after detection of head and neck metastasis; therefore, therapeutic decisions should maximize comfort and minimize morbidity considering the poor long-term prognosis at this stage of the disease.

Lymph node metastasis has long been known to be a poor prognostic factor in kidney cancer and is an important prognostic factor even in the presence of distant hematogenous metastasis. Lymph node involvement has a poor prognosis with a 5-year survival rate of 5-30\%, which happens to be similar to systemic metastases. In spite of studies suggesting benefit from extended lymph node dissection, there appears to be inconclusive data from controlled, randomized studies to support any surgical advantage [23]. Whether a patient will benefit lymph node dissection involving an early or isolated involvement of lymph nodes has yet to be investigated in controlled, randomized clinical studies.

Chemotherapy combined with interferon has shown to provide palliative benefit in some patients with RCC. One prospective trial compared and showed that in properly selected patients with metastatic disease, immunologic therapy following radical nephrectomy may improve time to progression. Nephrectomy combined with systemic cytokine gave a greater survival advantage over the group treated with only immunotherapy [24]. Nevertheless, immunologic agents are limited and often prematurely stopped due to their systemic side effects and toxicity.

Newer agents targeting the VEGF pathway such as bevacizumab and sorafenib have shown to improve progression-free survival in metastatic RCC [25, 26]. Early phase trials with bevacizumab and sorafenib may provide hope for cytokine-refractory patients with metastatic RCC.

Genitourinary tumors have been shown to metastasize to the head and neck region in rare instances. Therefore, the work-up of a new head or neck lesion in light of a history of genitourinary tumors should include metastases as part of the differential diagnosis. If a diagnosis of genitourinary metastases is established, additional therapeutic options, including immunotherapy, surgery, and chemotherapy should be discussed with the patient despite the poor prognosis.

Acknowledgments The authors acknowledge Ms. Lorraine Lozano for the preparation of manuscript.

Conflict of interest statement The authors declare that they have no stated conflicts of interest. Dr. Carol Bennett has a grant from Pfizer.

Open Access This article is distributed under the terms of the Creative Commons Attribution Noncommercial License which permits any noncommercial use, distribution, and reproduction in any medium, provided the original author(s) and source are credited.

\section{References}

1. Sankaranarayanan R, Masuyer E, Swaminathan R et al (1998) Head and neck cancer: a global perspective on epidemiology and prognosis. Anticancer Res 18:4779

2. Jemal A, Siegal R, Ward E et al (2008) Cancer statistics, 2008. CA Cancer J Clin 58:71 
3. Hessan H, Strauss M, Sharkey FE (1986) Urogenital tract carcinoma metastatic to the head and neck. Laryngoscope 96:13521356

4. Ferlito A, Shaha AR, Buckley JR, Buckley G, Caruso G, Rinaldo A (2001) Metastatic cervical lymph nodes from urogenital tract carcinoma: a diagnostic and therapeutic challenge. Acta Otolaryngol 121(5):556-564

5. Mintz E, Smith G (1934) Autopsy findings in 100 cases of prostatic cancer. N Engl J Med 211(11):478-487

6. Skarin A (2001) Unusual tumors involving the head and neck region. J Clin Oncol 19(21):4173-4179

7. Kundra V, Silverman PM, Matin SF et al (2007) Imaging in oncology from the University of Texas M.D. Anderson Cancer Center: diagnosis, staging, and surveillance of prostate cancer. AJR Am J Roentgenol 189(4):830-844

8. Telera S, Carloia S, Cavallotti D, Bosco S, Manni M, Ceconi L (2001) Sphenoidal metastasis from prostate carcinoma. Case report and review of literature. Neurochirurgie 47:61-65

9. Pienta KJ, Esper PS (1993) Risk factors for prostate cancer. Ann Intern Med 118:793-803

10. Mickel RA, Zimmerman MC (1990) The sphenoid sinus-a site for metastasis. Otolaryngol Head Neck Surg 102:709-716

11. Golimbu M, Joshi P, Sperber A, Tessler A, Al-Askari S, Morales P (1986) Renal cell carcinoma: survival and prognostic factors. Urology 27(4):291-301

12. Pritchyk KM, Schiff BA, Newkirk KA, Krowiak E, Deeb ZE (2002) Metastatic renal cell carcinoma to the head and neck. Laryngoscope 112(9):1598-1602

13. Som PM, Norton KL, Shugar JM, Reede DL, Norton L, Biller HF (1987) Metastatic hypernephroma to the head and neck. AJNR Am J Neuroradiol 8:1103-1106

14. Boles R, Cemy J (1971) Head and neck metastases from renal carcinomas. Mich Med 70:616-618

15. Will AT, Agarwal N, Petruzzelli GJ (2008) Oral cavity metastasis of renal cell carcinoma: a case report. J Med Case Rep 2:313
16. Maldazys JD, de Kernion JB (1986) Prognostic factors in metastatic renal carcinoma. J Urol 136:376

17. National Cancer Institute (2001) NCI Fact Book. NIH Publication No. 01-512. National Institutes of Health, Bethesda, MD

18. Cohen DM, Green JG, Diekmann SL et al (1989) Maxillary metastasis of transitional cell carcinoma: report of a case. Oral Surg Oral Med Oral Pathol 67:185-189

19. Doval DC, Naresh KN, Sabitha KS et al (1994) Carcinoma of the urinary bladder metastatic to the oral cavity. Indian J Cancer 31:811

20. Kopper A, Skinner DG, Calcaterra TC (1975) Carcinoma of the bladder metastatic to the tongue. Br J Urol 47:644

21. Edwab RR, Roberts MJ, Sole MS, Mahoney WD, Rapaport SC (1981) Metastasis of a transitional cell carcinoma of the bladder to the submandibular gland. J Oral Surg 39:972-974

22. Rabinovitch RA, Zelefsky MJ, Gaynor JJ, Fuks Z (1994) Patterns of failure following surgical resection of renal cell carcinoma: implication for adjuvant local and systemic therapy. J Clin Oncol 12:206-212

23. Phillips CK, Taneja SS (2004) The role of lymphadenectomy in the surgical management of renal cell carcinoma. Urol Oncol 22(3):214-223

24. Flanigan RC, Salmon SE, Blumenstein BA, Bearman SI, Roy V, McGrath PC, Caton JR, Munshi N, Crawford ED (2001) Nephrectomy followed by interferon alfa- $2 \mathrm{~b}$ compared with interferon alfa- $2 \mathrm{~b}$ alone for metastatic renal-cell carcinoma. N Engl J Med 345(23):1655-1659

25. Motzer RJ, Hutson TE, Tomczak P et al (2007) Sunitnib versus interferon alfa in metastatic renal-cell carcinoma. N Engl J Med 356(2): $115-124$

26. Escudier B, Eisen T, Stadler WM et al (2007) Sorafenib in advanced clear-cell renal-cell carcinoma. N Engl J Med 356(2):125134 